\title{
Dietary behavior and influencing factors among rural pregnant women in poverty-stricken West China, Sichuan Province: A cross-sectional study
}

\author{
Luo $B^{1 *}$, Liu $Y^{1}$, Peng $W^{1}$ and Feng $X^{2}$ \\ ${ }^{1}$ Department of Gynecology and Obstetrics, West China Second University Hospital, Sichuan University, Chengdu, Sichuan, People's Republic of China \\ ${ }^{2}$ College of Nursing, Chengdu Polytechnic, Chengdu, Sichuan, People's Republic of China
}

\begin{abstract}
Aim: To understand the dietary behavior and influencing factors among rural pregnant women in poverty-stricken areas of West China.

Methods: Based on the Theory of Reasoned Action (TRA), literature review, preliminary investigation, and expert evaluation, we designed and finalized a self -administered questionnaire. The Structural Equation Model (SEM) was used to identify the influencing factors of dietary behavior comprehensively.

Results: Pregnant women in rural areas took rice, vegetables and fruits as the principal food. Compared with the national recommendation, they took milk, bean products, fishes and nuts less frequently. For pregnant women in rural areas, their dietary behavior differed in some aspects between pre-pregnancy and pregnancy. Compared with pre-pregnancy, women paid more attention to breakfast during pregnancy $(\mathrm{P}<0.05)$. The behaviors of smoking, drinking, and fried foods eating were less frequent $(\mathrm{P}<0.05)$; but drinking, smoking, and passive smoking were still observed in pregnant women. Dietary behavior of pregnant women was decided by behavioral intention (standardized regression coefficient was 0.435 ); and behavioral attitude and subjective norm affected dietary behavior by influencing behavioral intention eventually (standardized regression coefficients were 0.268 and 0.524 ).
\end{abstract}

Conclusions: The dietary structure of rural pregnant women in poverty-stricken areas of West China was irrational, and their diet behaviors were affected by their own attitude and subjective norms. Measures should be taken to improve the dietary behaviors of pregnant women in rural areas of West China.

\section{Introduction}

Maternal nutrition affects fetal growth and birth outcomes [1,2]. Nutrition studies described that both under-nutrition and overnutrition during pregnancy will increase the health risks of offspring $[3,4]$. Healthy dietary behaviors during pregnancy could supply necessary nutrients to pregnant women and have a powerful impact on their health and on fetal development. By contrast, unhealthy dietary behaviors are associated with an increased risk of morbidity and mortality in the adulthood of offspring [5-7]. Poor nutrition during pregnancy is a major public health problem in rural areas of China. A prospective cohort study of 20,000 pregnant women in Anhui Province conducted by Xing XY etc. found that rural pregnant women prefer to select the type of "low health" diet [8]. Li YY's survey among urban and rural pregnant women in Shandong Province showed that the intakes of fruits, vegetables, fishes, poultries, beans, and nuts were inadequate in rural pregnant women [9]. Both results reveal a prevalence phenomenon that rural pregnant women did not have adequate intakes of important nutrients and their dietary structure was unreasonable.

Dietary behaviors of pregnant women were affected by many factors. Many studies confirmed that culture and economic level were the significant factors influencing quantity and nutrients of the diet of pregnant women [10-13]. Two surveys in Poland reported that dietary behaviors among rural pregnant women were mainly affected by lacking of nutrition knowledge, and a study in Sweden also indicated that education level, age, social class, nutrition knowledge and attitude were associated with dietary behavior during pregnancy, rural pregnant women were susceptible to the influence of traditional concepts and thus practiced unhealthy eating behaviors [14-16]. Some studies in China suggested that the dietary behaviors of rural pregnant women were mainly related to traditional habits, lacking of nutrition knowledge, cultural and geographical restrictions, lower socioeconomic status and education level, etc. $[8,9,17,18]$.

Despite these findings, however, most studies are not comprehensive because many had methodological limitations such as lack of theoretical basis. In addition, few studies have reported the dietary behavior and influencing factors of pregnant women in rural areas of West China, where many provinces are predominantly agricultural and living conditions and health services are relatively poor when comparing with other regions of the country. Therefore, we designed the current study based on the Theory of Reasoned Action (TRA). We aimed to analyze the influencing factors of dietary behaviors among pregnant women in rural areas of West China and to identify specific interventions for optimizing pregnancy outcomes.

Correspondence to: Biru Luo, Department of Nursing, West China Second University Hospital, Sichuan University, Chengdu, Sichuan, People's Republic of China, Tel: +86 28 85503852; Fax: +8628 85503776; E-mail: 13438485733@163.com

Key words: pregnant women, rural areas; dietary behavior; theory of reasoned action, structural equation model

Received: December 01, 2016; Accepted: December 22, 2016; Published: December 26, 2016 


\section{Methods}

TRA was proposed in 1967 for the first time by Fishbein [19], a United States scholar, which believes that in the psychological processes of performing a behavior, the most directed factor is whether people are going to implement this behavior, named behavioral Intention, and individual's behavioral intention are determined by behavioral attitudes and subjective norms. The framework of TRA was shown in Figure 1.

Based on TRA, literature review and expert evaluation, we designed the questionnaire that was tailored to our research objectives. A total of 50 participants were recruited to complete the questionnaires as a pilot investigation. After pre-survey and expert's revision, the questionnaire was finalized as investigation on dietary behaviors among pregnant women in rural areas of China and analysis of influencing factors. The questionnaire consists of general information which included the participants' age, education, occupation, prenatal Body Mass Index (BMI), education level of primary caretakers, prenatal check-times and dietary behavior, food frequency which was based on the simplified semi-quantitative food frequency, and food which was categorized as nine groups including grain, meat, vegetable, and fruit etc. as specified in "The Balanced Diet Guideline for the Chinese Population" [20]. It took $20 \sim 30$ minutes to complete the questionnaire. The Cronbach's a coefficient of the questionnaire was 0.817 , and the average value of content validity was 0.975 .

According to the reference, $54 \%$ of rural pregnant women in China were facing the risk of inadequate dietary intakes [21]. The number of samples was about 400 as calculated with the following formula:

$$
n=\left(\frac{Z_{\alpha / 2}}{\delta}\right)^{2} \pi(1-\pi)
$$

In the formula, $\alpha=0.05, \mathrm{Z}_{0.05 / 2}=1.96, \delta$ means permissible error, valued $5 \%$,

$$
\pi=0.54 \text {. }
$$

$$
n=\left(\frac{1.96}{0.05}\right)^{2} \times 0.54 \times 0.46=382 \approx 400
$$

Given $20 \%$ of losing rate, the total sample size was about 500 .

The study was conducted from August 1, 2013 to November 30, 2013 in Sichuan Province, where is a miniature of West China with regard to geographic features, economic conditions, and cultural diversity. According to the geographical distribution of Sichuan, we selected four national-level poverty counties (Pingshan, Nanbu, Cangxi, and Guang'an) that are located in mid-, northern, southern, and eastern Sichuan, respectively. We recruited 500 pregnant women (125 for each county) from the people's hospital and maternal and child health care center of each of the four selected counties. In each target hospital and center, we trained a senior obstetrical nurse as research assistant. The pregnant women were coached on a one-onone basis by researchers and were showed common food standard models or patterns before filling the questionnaires by themselves. All participants met the following inclusion criteria: over 18 years of age, volunteer for this study, and with normal cognitive ability. Exclusion criteria were: having severe pregnancy-related complications, nonsingleton pregnancy. Ethical approval was granted by west China second university hospital ethics committees, and written consent was obtained.

SEM, also known as latent variable model, is a significant quantitative research method in the fields of contemporary behavioral and social, it's equation include random variables (observed variables, latent variables and error variable) and structural parameters. It was mainly used to analyze the complex relationships among the observed variables, in particular to explore the potential relationships. This study was based on the TRA, therefore, the relationships among latent variables of the initial model include the effects of behavioral attitudes and subjective norms on behavioral intention, and the direct effect of behavioral attitudes, subjective norms and behavioral intention on behavior. We draft SEM by visualization software modules AMOS (analysis of moment structures), after adaptation and revision, we output the final model. Involved variables were shown in Table 1.

\section{Statistical analysis}

Excel was used to establish the database, and SPSS17.0 and Amos21.0 (2011 Flexera software) were used for statistical analysis. Rate, constituent ratio, and mean were used to describe the social and

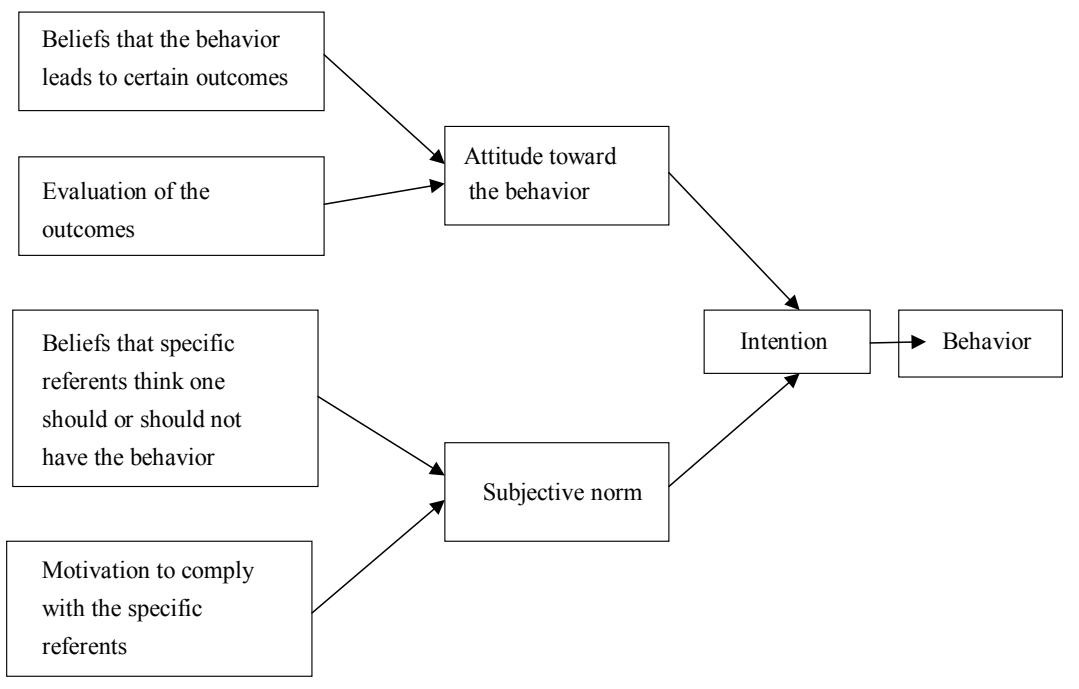

Figure 1. The Theory of Reasoned Action (TRA) Model.

TRA believes that in the psychological processes of performing a behavior, the most directed factor is whether people are going to implement this behavior, named behavioral Intention, and individual's behavioral intention are determined by behavioral attitudes and subjective norms. 
Table 1. Variables involved in Structural Equation Model.

\begin{tabular}{|c|c|}
\hline Latent Variables (Code) & Observed variables (Code) \\
\hline \multirow[t]{3}{*}{ (Behavior) } & $\begin{array}{l}\text { Eat breakfast(B1) } \\
\text { Supplement calcium in sense(B2) } \\
\text { Supplement iron in sense(B3) } \\
\text { Whether change eating habits in sense(B4) }\end{array}$ \\
\hline & $\begin{array}{l}\text { Drink tea(B5) } \\
\text { Eat fried foods(B6) }\end{array}$ \\
\hline & $\begin{array}{l}\text { Drinking(B7) } \\
\text { Smoking(B8) } \\
\text { Whether have food preference(B9) }\end{array}$ \\
\hline \multirow[t]{2}{*}{ (Cognition) } & Know the benefits of balanced $\operatorname{diet}(\mathrm{C} 1)$ \\
\hline & Know the dangers of poor $\operatorname{diet}(\mathrm{C} 2)$ \\
\hline \multirow[t]{4}{*}{ (Attitude) } & $\begin{array}{l}\text { Maternal belief to dietary behavior } \\
\text { during pregnancy }\end{array}$ \\
\hline & Beliefs between Proper diet and mother and child's health(A1) \\
\hline & Maternal evaluation about outcomes of dietary behavior during pregnancy \\
\hline & Importance of a healthy diet during pregnancy to mother and child(A2) \\
\hline (Subjective Norm) & $\begin{array}{l}\text { Husband: Husband's faith of dietary behavior (S1) } \\
\text { Maternal compliance with recommendations of husband(S2) } \\
\text { Mother: mother's faith of dietary behavior(S3) } \\
\text { Maternal compliance with recommendations of mother(S4) } \\
\text { Mother-in law: mother-in-law's faith of dietary behavior(S5) } \\
\text { Maternal compliance with recommendations of mother-in-law(S6) } \\
\text { Companion: Companion's faith of health care behavior(S7) } \\
\text { Maternal compliance with recommendations of Companion(S8) }\end{array}$ \\
\hline (Intention) & $\begin{array}{l}\text { Do you want to take dietary behavior? (I1) } \\
\text { Do you think the dietary behavior is beneficial to you? (I2) }\end{array}$ \\
\hline Others & $\begin{array}{l}\text { Whether the pregnant accept dietary guidance from medical workers? (X1) } \\
\text { Education level of caretaker(X2) } \\
\text { Income per month(X3) } \\
\text { Prenatal check-times(X4) } \\
\text { Education level of the pregnant(X5) } \\
\text { Did you plan to get pregnant? (X6) }\end{array}$ \\
\hline
\end{tabular}

demographic data of the pregnancy women. SEM was used to identify the influencing factors of the eating behavior of pregnant women. $\mathrm{P}<0.05$ was considered statistically significant.

\section{Results}

\section{The demographic data of participants}

The social and demographic data of participants in the four rural counties were similar. Participants aged between 18 and 34 years old mainly. Most of them were Han nationality, and most of them were not medical workers. The education level of most participants was junior high school, similar to that of their main caregivers. Most of the pre-pregnancy BMI were within the normal range. Primipara and multipara constituted $50 \%$ each. Women who did not obtain dietary guidance during pregnancy from the medical workers accounted for $60.61 \%$ (Table 2).

\section{Dietary behaviors of participants}

Pregnant women in rural areas took rice, vegetables and fruits as the principal food. The intakes of milk, bean products, fishes and nuts were not enough, about $20 \%$ women never intook daily products and bean products. Women who never in took nutritional supplements accounted for $47.96 \%$ (Table 3).

Dietary behaviors of pregnant women in rural areas differed between pre-pregnancy and pregnancy. Compared with prepregnancy, women during pregnancy paid more attention to breakfast $(P<0.05)$. The behaviors of smoking, drinking, fried foods eating was less frequent $(\mathrm{P}<0.05)$, but drinking, smoking, and passive smoking were still observed in pregnant women (Table 4 ).

\section{Influencing factors of dietary behaviors}

Establishment and Amendment of SEM: According to the results of the initial model, Adjustments were as follows: (1) deleted the path between B5 B9 and dietary behavior; (2) delete the influence path of X3 on attitudes and intention; (3) delete the path between X6 and dietary behavior; (4) establish the direct impact path of X5 on the eating behavior; (5) establish the path between X1 and X4, between X2 and X5, between e1 and e2, between e7 and e8, between e16 and e17. Finally, the modified model was shown in Figure 2. The compare of initial model and final model were presented in Table 5.

Report on the results of model parameters: The final model showed that the dietary cognition of pregnant women was significantly associated with behavioral attitude, with the standardized regression coefficient being 0.503 . Behavioral attitude and the subjective norm had a direct impact on behavioral intention, with the standardized regression coefficients being 0.268 and 0.524 , respectively. Subjective norm affected dietary behavior indirectly by influencing attitude directly, with the standardized regression coefficient being 0.376 . Besides, behavioral intention related directly to dietary behavior, with the standardized regression coefficient being 0.435 . Whether pregnant women acquired guidance of diet from medical workers was associated with dietary behavior by influencing the subjective norms indirectly, the same as the education level of primary caregivers (standardized regression coefficients being 0.215 and 0.134 ). The education level of pregnant women had a positive impact on cognition, with the standardized regression coefficient being 0.418. Prenatal check times affected dietary behavior directly, with the standardized regression coefficient being 0.478 . 
Table 2. The demographic data of pregnant women in China's rural area.

\begin{tabular}{|c|c|c|c|c|c|c|c|c|c|}
\hline \multicolumn{2}{|l|}{ Variables } & \multicolumn{2}{|c|}{$\begin{array}{c}\text { Pingshan County } \\
\text { Number } \%\end{array}$} & \multicolumn{2}{|c|}{$\begin{array}{l}\text { Nanbu County } \\
\text { Number\% }\end{array}$} & \multicolumn{2}{|c|}{$\begin{array}{l}\text { Cangxi County } \\
\text { Number\% }\end{array}$} & \multicolumn{2}{|c|}{$\begin{array}{c}\text { Guang'an Region } \\
\text { Number\% }\end{array}$} \\
\hline \multirow[t]{2}{*}{ Age } & \multirow{2}{*}{$\begin{array}{l}18-34 \text { ys } \\
\geq 35 y s\end{array}$} & 114 & 91.20 & 109 & 89.34 & 114 & 92.68 & 111 & 92.5 \\
\hline & & 11 & 8.80 & 13 & 10.66 & 9 & 7.32 & 9 & 7.50 \\
\hline \multirow{5}{*}{$\begin{array}{l}\text { Education } \\
\text { level }\end{array}$} & Illiteracy & 1 & 0.80 & 0 & 0.00 & 0 & 0.00 & 1 & 0.83 \\
\hline & Primary & 29 & 23.20 & 6 & 4.92 & 14 & 11.38 & 12 & 10.0 \\
\hline & Junior high & 69 & 55.20 & 61 & 50.00 & 47 & 38.21 & 66 & 55.0 \\
\hline & Senior high & 20 & 16.00 & 37 & 30.33 & 42 & 34.15 & 25 & 20.83 \\
\hline & College and above & 6 & 4.80 & 18 & 14.75 & 20 & 16.26 & 16 & 13.34 \\
\hline \multirow[t]{4}{*}{ Pre-pregnancy BMI } & $<18.5$ & 28 & 22.40 & 33 & 27.05 & 45 & 36.59 & 33 & 27.50 \\
\hline & $18.5 \sim 24.9$ & 88 & 70.40 & 81 & 66.39 & 66 & 53.66 & 79 & 65.83 \\
\hline & $25.0 \sim 29.9$ & 9 & 7.20 & 8 & 6.56 & 12 & 9.75 & 6 & 5.00 \\
\hline & $\geq 30.0$ & 0 & 0.00 & 0 & 0.00 & 0 & 0.00 & 2 & 1.67 \\
\hline \multirow[t]{2}{*}{ Ethnicity } & Han & 122 & 97.60 & 120 & 98.36 & 123 & 100.00 & 115 & 95.83 \\
\hline & Others & 3 & 2.40 & 2 & 1.64 & 0 & 0.00 & 5 & 4.17 \\
\hline \multirow[t]{2}{*}{ Profession } & Medical worker & 2 & 1.60 & 2 & 1.64 & 8 & 6.50 & 2 & 1.67 \\
\hline & Non-medical worker & 123 & 98.40 & 120 & 98.36 & 115 & 93.50 & 118 & 98.33 \\
\hline \multirow[t]{2}{*}{ Maternal history } & Primipara & 65 & 51.20 & 69 & 56.56 & 65 & 52.85 & 66 & 55.00 \\
\hline & Multipara & 60 & 48.00 & 53 & 43.44 & 58 & 47.15 & 54 & 45.00 \\
\hline \multirow[t]{2}{*}{ Getting advice from caregivers } & yes & 42 & 33.60 & 54 & 44.26 & 55 & 44.72 & 42 & 35.00 \\
\hline & no & 83 & 66.40 & 68 & 55.74 & 68 & 55.28 & 78 & 65.00 \\
\hline \multirow[t]{2}{*}{ Antenatal visits } & $<5$ times & 64 & 51.20 & 40 & 32.79 & 33 & 26.83 & 58 & 48.33 \\
\hline & $\geq 5$ times & 61 & 48.80 & 82 & 67.21 & 90 & 73.17 & 62 & 51.67 \\
\hline \multirow[t]{5}{*}{ Education level of Caretakers } & Illiteracy & 12 & 9.60 & 8 & 6.56 & 9 & 7.32 & 5 & 4.17 \\
\hline & Primary & 36 & 28.80 & 47 & 38.52 & 41 & 33.33 & 32 & 26.67 \\
\hline & Junior high & 56 & 44.80 & 46 & 37.70 & 40 & 32.52 & 56 & 46.67 \\
\hline & Senior high & 15 & 12.00 & 14 & 11.48 & 23 & 18.70 & 19 & 15.83 \\
\hline & College and above & 6 & 4.80 & 7 & 5.74 & 10 & 8.13 & 8 & 6.67 \\
\hline
\end{tabular}

Table 3. The food consumption frequency of pregnant women in China's rural area.

\begin{tabular}{|c|c|c|c|c|c|}
\hline Variety of Food & Never eat & 1 3 times / month & 1 3 times / week & 4 6 times/week & Everyday \\
\hline Rice & $1(0.20)$ & $17(3.47)$ & $14(2.86)$ & $16(3.27)$ & $442(90.20)$ \\
\hline Grains & $23(4.69)$ & $168(34.29)$ & $132(26.94)$ & $62(12.65)$ & $105(21.43)$ \\
\hline Potato & $45(9.18)$ & $198(40.41)$ & $149(30.41)$ & $62(12.65)$ & $36(7.35)$ \\
\hline Vegetable & $6(1.23)$ & $32(6.53)$ & $61(12.45)$ & $62(12.65)$ & $329(67.14)$ \\
\hline Fruits & $8(1.63)$ & $37(7.55)$ & $58(11.84)$ & $71(14.49)$ & $316(64.49)$ \\
\hline Meat & $29(5.92)$ & $60(12.24)$ & $81(16.53)$ & $71(14.49)$ & $249(50.82)$ \\
\hline Fishes & $88(17.96)$ & $184(37.55)$ & $147(30.00)$ & $44(8.98)$ & $27(5.51)$ \\
\hline Eggs & $47(9.59)$ & $92(18.78)$ & $134(27.34)$ & $93(18.98)$ & $124(25.31)$ \\
\hline Dairy products & $99(20.20)$ & $110(22.45)$ & $114(23.27)$ & $73(14.90)$ & $94(19.18)$ \\
\hline Bean products & $94(19.18)$ & $171(34.90)$ & $133(27.14)$ & $48(9.80)$ & $44(8.98)$ \\
\hline Nuts & $69(14.08)$ & $182(37.14)$ & $158(32.25)$ & $51(10.41)$ & $30(6.12)$ \\
\hline Nutritional Supplements & $235(47.96)$ & $103(21.02)$ & $79(16.12)$ & $38(7.76)$ & $35(7.14)$ \\
\hline
\end{tabular}

Table 4. Comparison of dietary behaviors between pre-pregnancy and pregnancy.

\begin{tabular}{|c|c|c|c|c|c|c|c|c|c|c|c|c|}
\hline \multirow[t]{2}{*}{ Variable } & \multicolumn{5}{|c|}{ Pre-pregnancy $(n=490)$} & \multicolumn{5}{|c|}{ Pregnancy $(n=490)$} & \multirow[b]{2}{*}{$Z$} & \multirow[b]{2}{*}{$P$} \\
\hline & Never & Occasionally & Sometimes & Often & Everyday & Never & Occasionally & Sometimes & Often & Everyday & & \\
\hline Eat breakfast & 17 & 65 & 39 & 82 & 287 & 2 & 26 & 10 & 43 & 409 & -9.907 & $0.000^{*}$ \\
\hline Eat lunch & 3 & 6 & 9 & 27 & 445 & 0 & 3 & 1 & 22 & 464 & -3.659 & $0.000^{*}$ \\
\hline Eat dinner & 0 & 8 & 10 & 18 & 454 & 1 & 5 & 6 & 22 & 456 & -0.846 & 0.398 \\
\hline Drink tea & 193 & 186 & 65 & 26 & 20 & 354 & 90 & 28 & 12 & 6 & -11.043 & $0.000^{*}$ \\
\hline Drink coffee & 328 & 118 & 31 & 11 & 2 & 441 & 25 & 20 & 3 & 1 & -7.491 & $0.000^{*}$ \\
\hline Drink Cola & 232 & 193 & 53 & 11 & 1 & 392 & 71 & 24 & 3 & 0 & -10.464 & $0.000 *$ \\
\hline Drinking & 325 & 113 & 38 & 11 & 3 & 451 & 27 & 12 & 0 & 0 & -9.939 & $0.000^{*}$ \\
\hline Smoking & 400 & 37 & 40 & 8 & 5 & 443 & 28 & 15 & 4 & 0 & -5.225 & $0.000^{*}$ \\
\hline Passive smoking & 124 & 67 & 112 & 95 & 92 & 192 & 106 & 95 & 65 & 32 & -10.757 & $0.000 *$ \\
\hline Eating nuts & 43 & 220 & 148 & 75 & 4 & 57 & 193 & 131 & 71 & 38 & -2.597 & $0.009 *$ \\
\hline Eat cured foods & 24 & 192 & 141 & 122 & 11 & 53 & 279 & 105 & 46 & 7 & -9.406 & $0.000 *$ \\
\hline Eat fried foods & 122 & 242 & 101 & 25 & 0 & 210 & 228 & 43 & 9 & 0 & -8.675 & $0.000 *$ \\
\hline
\end{tabular}

Note: *means the difference was statistically significant. 
Table 5. Comparison of fit index between Initial model and final model

\begin{tabular}{|l|c|c|c|c|c|c|}
\hline & $\chi^{2}$ & $\chi^{2} / \mathbf{d f}$ & CFI & PCFI & NFI & PNFI \\
\hline Initial model & 1828.944 & 4.917 & 0.682 & 0.625 & 0.634 & 0.581 \\
\hline final model & 748.953 & 3.764 & 0.870 & 0.749 & 0.089 \\
\hline Criteria & The smaller the better & $<5$ & $>0.90$ & $>0.50$ & 0.717 & $>0.90$ \\
\hline
\end{tabular}

Note: $\chi^{2}$ value; df: Degree Freedom; CFI: Comparative Fit Index; PCFI: The CFI After Adjusted Freedom Degree; NFI: Normed Fit Index; PNFI: The NFI After Adjusted Freedom Degree; RMSEA: Root Mean Square Error of Approximation

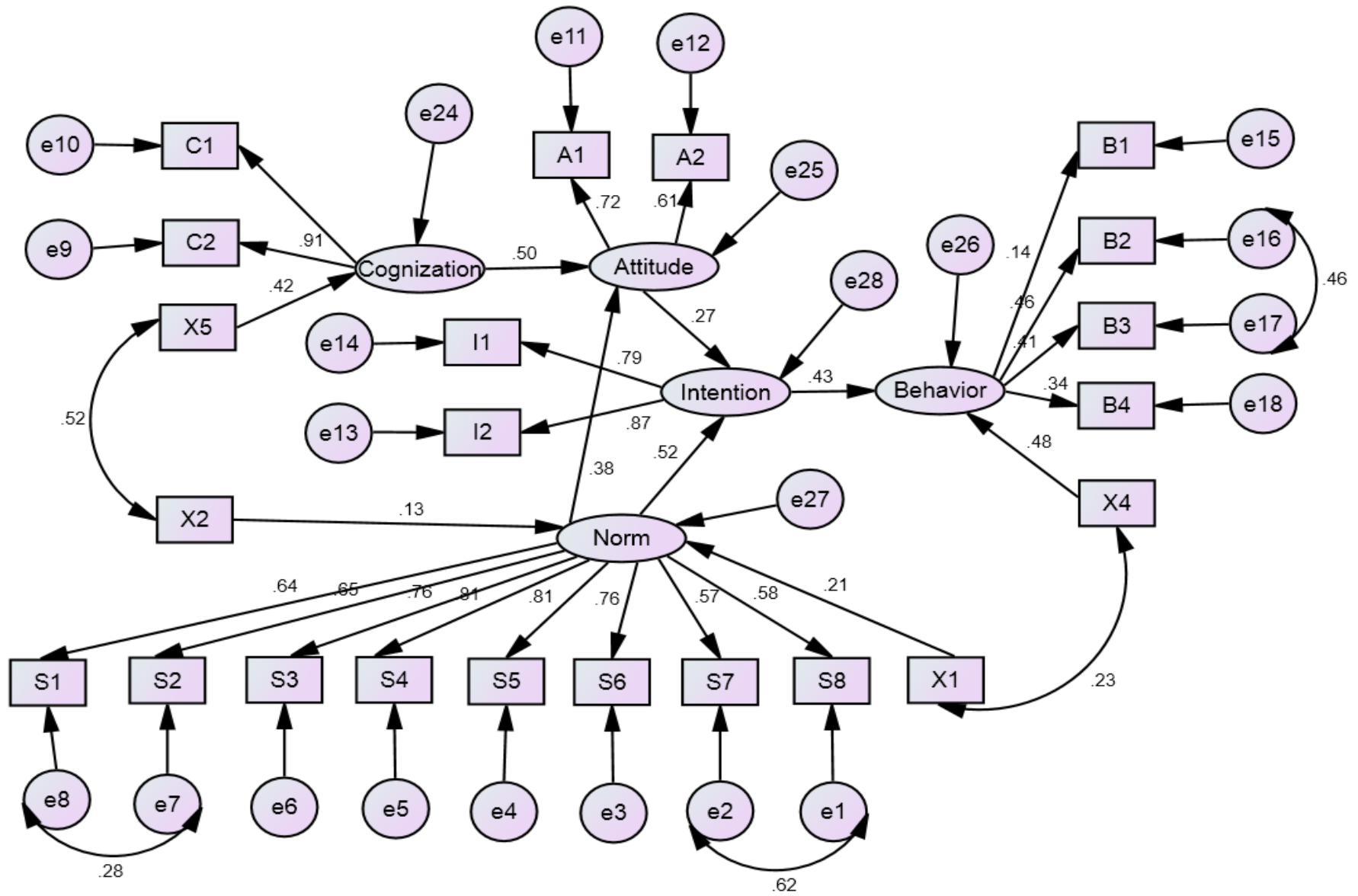

Figure 2. Final structural equation model of factors associated with diet behavior among rural pregnant women.

SEM was drafted by visualization software modules AMOS (analysis of moment structures), which also called latent variable model, it is an important statistical method of quantification research in the fields of contemporary behavior and society. Its equation contains random variables (observed variables, latent variables and error variables) and structural parameters. It is mainly used to analyze the complex relationships among observed variables, in particular, to explore the relationship of potential variables.

\section{Discussion}

The study showed that the dietary behaviors of rural pregnant women improved generally in mid and late trimester when comparing with pre-pregnancy, which attributed to the strengthening of maternal's health awareness during pregnancy. But their intakes of some necessary nutrients were lower than national recommendation, especially the dairy products, bean products, fish, nuts and nutritional supplements. These results are in accordance with the outcomes of Suliga which showed that pregnant women in rural more rarely consumed sea fish, milk and dairy products [14]. Low education level, lack of nutrition knowledge and lack of sufficient financial resources for the purchase of the necessary products significantly limited the consumption by pregnant women of above foods. Besides, nearly $10 \%$ of rural pregnant women did not guarantee daily intake of staple food. According to the recommendation, staple food can provide $50 \%-60 \%$ of energy in oneday diet, while deficiency of staple food would affect health adversely
[22]. We also found some delinquencies among pregnant women, such as drinking, smoking, and passive smoking. Drinking and smoking have been confirmed dangerous for pregnancy and fetal development [23]. A large number of studies have shown that smoking during pregnancy induced premature, low birth weight, placental complications, and asthma, and the risks of stillbirth and early death of neonatal were also increased [24-26]. Therefore, it is necessary to encourage and help pregnant women to quit these detrimental habits.

According to the SEM analysis results, pregnant women's behavioral attitude was influenced by their cognition and was determined by whether or not knowing the benefits of balanced diet and the dangers of poor diet. A study conducted by Jin WJ [27] confirmed that personalized educational interventions could improve the pregnant women's dietary behaviors. Moreover, a previous study also suggested that education was positively associated with the dietary behaviors of pregnant women $[23,27]$. In our study, the maternal's education level were low and we 
concluded that the unbalanced diet status of pregnant women was linked to the lacking of reasonable dietary knowledge. Therefore, it is necessary to carry out health education among rural pregnant women in the area of adequate nutrition, we should inform them the benefits of a balanced diet on mother and infant, with particular emphasis on the dangers of poor diet. The improvements in knowledge can lead to behavioral changes among rural pregnant women in poverty-stricken counties of West China.

We also found that pregnant women's dietary behaviors were severely influenced by the attitude of some other people, who were known as subjective norm, such as their husband, mother, motherin-law, relatives and friends. The subjective norm also affected diet behavior ultimately by influencing women's attitude, which confirms the results of Luo's study on influencing factors of dietary behaviors among urban pregnant women in China [28]. Other studies have also shown that women's concept of diet was deeply influenced by people around them, who may lead them to unscientific attitude $[29,30]$. In our study, mother and husband as the main caregivers, were influenced by traditional Chinese culture, and advised pregnant women to hold on some taboos, such as avoiding rabbit meat, beef and lamb, which were widely considered to be healthy and nutritious food choices [31]. A study of Lee et al. [32] pointed out that the family members were the most important channels for imparting antenatal taboos to pregnant women. Therefore, it is very crucial to educate the care givers, generally the pregnant women's mother, husband, mother-in-law, and other family members as well as the pregnant women themselves. In addition, people such as neighbors and friends should also be given health education to improve the pregnant women's diet behaviors.

Behavioral Intention is a trend of intent, a kind of motive and mindset before performing a behavior [33]. The observed variables of behavior intention were whether they are willing to take the dietary behavior and whether they think taking this diet behavior is beneficial to them. The behavioral intention could maintain a certain behavior ${ }^{[34]}$ which reminds us that the benefits of proper diet should be publicized to encourage the pregnant women to take reasonable diet behaviors and help them to endorse it viscerally and take action voluntarily, thereby form positive behavioral intentions.

Using TRA, we were able to investigate and analyze the status and influencing factors of dietary behavior among rural pregnant women in the poverty-stricken counties of West China-Sichuan province comprehensively and thoroughly. The study also benefitted from the use of SEM to explore factors associated with pregnant women's eating behavior and to explore the potential relationships among these factors. Two limitations of the study should be considered in the interpretation of its findings. First, the survey was conducted in the poverty-stricken counties of Sichuan province only and used typical sampling; thus, our results may not be suitable for extrapolation. Second, the measurement method of dietary intakes was based on semi-quantitative due to some limitations existing; so, our research has not been excavated the complete information.

In conclusion, the dietary structure of rural pregnant women in poverty-stricken counties of West China was irrational, the application of SEM revealed the direct effect of behavioral intention on dietary behavior, particularly cleared a major indirect influence of subjective norms on dietary behavior, which pointed out a clear direction of health education for future that measures should be taken to improve the dietary behaviors of pregnant women in rural areas of West China ,both government and $\mathrm{MCH}$ should pay more attention on rural pregnant women.

\section{References}

1. Abu-Saad K, Fraser D (2010) Maternal nutrition and birth outcomes. Epidemiol $\operatorname{Rev}$ 32: 5-25. [crossref]

2. Arzoaquoi SK, Essuman EE, Gbagbo FY, Tenkorang EY, Soyiri I, et al. (2015) Motivations for food prohibitions during pregnancy and their enforcement mechanisms in a rural Ghanaian district. Journal of Ethnobiology and Ethnomedicine11:59.

3. Suliga E (2015) Nutritional behaviours of pregnant women in rural and urban environments. Ann Agric Environ Med 22: 513-517.[crossref]

4. Koletzko B (2012) Impact of maternal obesity on long-term health outcomes. The 112th Abbott Nutrition Research Conference10-10.

5. Zeisel SH (2009) Epigenetic mechanisms for nutrition determinants of later health outcomes. Am J ClinNutr 89: 1488S-1493S. [crossref]

6. Keenan K, Bartlett TQ, Nijland M, Rodriguez JS, Nathanielsz PW, et al. (2013) Poor nutrition during pregnancy and lactation negatively affects neurodevelopment of the offspring: evidence from a translational primate model.Am J ClinNutr98:396-402. [crossref]

7. Olafsdottir AS, Skuladottir GV, Thorsdottir I, Hauksson A, Thorgeirsdottir H, et al (2006) Relationship between high consumption of marine fatty acids in early pregnancy and hypertensive disorders in pregnancy. BJOG 113: 301-309.[crossref]

8. Xin XY (2010) A cohort study of pregnant women eating patterns and associated with pregnancy outcomes. Anhui Medical University.

9. Li YY (2011) Compare analysis among urban and rural areas in Shandong Province of maternal health and postpartum diet. Qingdao University. [in Chinese]

10. Monsivais P, Aggarwal A, Drewnowski A (2012) Are socio-economic disparities in diet quality explained by diet cost? J Epidemiol Community Health 66: 530-535. [crossref]

11. Kriaucioniene V, Klumbiene J, Petkeviciene J, Sakyte E (2012) Time trends in social differences in nutrition habits of a Lithuanian population: 1994-2010. BMC Public Health 12: 218.[crossref]

12. Watson PE, McDonald BW (2009) Major influences on nutrient intake in pregnant New Zealand women. Matern Child Health J 13: 695-706. [crossref]

13. Suliga E (2013) Economic and social factors and the quality of nutrition ofpregnant women. Med St29: 160-166.

14. Suliga E (2015) Nutritional behaviours of pregnant women in rural and urban environments. Ann Agric Environ Med 22: 513-517. [crossref]

15. Wojtyla A, Bojar I, Boyle P, Zatoński W, Marcinkowski JT, et al. (2011) Nutritional behaviours among pregnant women from rural and urban environments in Poland. Ann Agric Environ Med18:169-174.[crossref]

16. Wennberg AL, Lundqvist A, Högberg U, Sandström H, Hamberg K (2013) Women's experiences of dietary advice and dietary changes during pregnancy. Midwifery 29: 1027-1034. [crossref]

17. Wang XS (2012) Analysis of 164 cases of pregnant women in different dietary and nutritional status. China Maternal and Child Health27:2442-2443.[in Chinese]

18. Lv HH (2010) KAP analysis of Zhengzhou maternal on nutritional status and dietary nutrition-related knowledge. Zhengzhou University.[in Chinese]

19. Ma X (2012) Health education.Beijing: People's Medical.

20. The Chinese nutrition society, women's and children's section (2008) Dietary guidelines for Chinese women in pregnancy, lactation period and $0 \sim 6$ years old children. Beijing People's Medical Publishing House: 2.

21. Cheng Y, Dibley MJ, Zhang X (2009) Assessment of dietary intakes Among pregnant women in a rural area of western China. BMC Public Health 9:222-231.

22. Hu CQ (2011) It is unhealthy if we don't eat staple food. People's Life8: 50-50. [in Chinese]

23. Murakami K, Miyake Y, Sasaki S, Tanaka K, Ohya Y, et al. (2009) Education, but not occupation or household income, is positively related to favorable dietary intakes patterns in pregnant Japanese women: the Osaka Maternal and Child Health Study. Nutrition Research 29: 164-172.[crossref]

24. Hollams EM, de Klerk NH, Holt PG, Sly PD (2014) Persistent effects of materna smoking during pregnancy on lung function and asthma in adolescents. Am J RespirCrit Care Med 189: 401-407.[crossref] 
25. Baba S, Wikström AK, Stephansson O, Cnattingius S (2014) Influence of snuff and smoking habits in early pregnancy on risks for stillbirth and early neonatal mortality. Nicotine TobRes 16: 78-83.[crossref]

26. Lumley J, Chamberlain C, Dowswell T, Oliver S, Oakley L, et al. (2009) Interventions for promoting smoking cessation during pregnancy. Cochrane Database Syst Rev: CD001055.[crossref]

27. Jin WJ, Huang Y, Luo BR (2015) The effect of a personalized intervention on weigh gain and physical activity among pregnant women in China.International Journal of Gynecology and Obstetrics 1:138-141.

28. Luo BR (2013) A study of diet and exercise behavior among Urban maternals as well as health education intervention.Sichuan University.

29. Hu QQ, Wang WL, Chi JH (2012) Analysis on nutrition knowledge and influence factors of pregnant women in third trimester. Journal of Nursing 19:34-36. [in Chinese]
30. Chen YZ, Xu H, Tang XJ (2013) Analysis of prenatal care status and influence factors among some ethnic minority areas in western China. Journal of Huazhong Science and Technology University (Medical Science) 42:346-350.[in Chinese]

31. Gao H, Stiller CK, Scherbaum V, Biesalski HK, Wang Q, et al. (2013) Dietary intake and food habits of pregnant women residing in urban and rural areas of Deyang City, Sichuan Province, China. Nutrients 5: 2933-2954.[crossref]

32. Lee DT, Ngai IS, Ng MM, Lok IH, Yip AS, et al. (2009) Antenatal taboos among Chinese women in Hong Kong. Midwifery 25: 104-113.[crossref]

33. Yang YZ (2007) Health behaviour theory and study.Beijing: People's Medica Publishing House 38-40.[Chapter in book]

34. Xie YP (2013) Survey on nutrition knowledge and influencing factors analysis on midlate pregnant women. China Health Care and Nutrition 01:400.

Copyright: $(02016$ Luo B. This is an open-access article distributed under the terms of the Creative Commons Attribution License, which permits unrestricted use, distribution, and reproduction in any medium, provided the original author and source are credited. 